\title{
ESTABLECIENDO PRECISIONES ENTRE LA ETAPA EJECUTORIA Y EL PROCESO DE EJECUCIÓN
}

\author{
Beatriz A. Franciskovic Ingunza
}

\begin{abstract}
RESUMEN
Por medio del presente artículo se trata de diferenciar cuando nos encontramos dentro de la etapa ejecutoria de un proceso judicial a diferencia del proceso de ejecución. Por el primero, se desarrolla el iter procesal, se inicia con la interposición de una demanda hasta la expedición de una sentencia, el juez resolverá sobre el conflicto declarando fundado, infundado o excepcionalmente improcedente la demanda, esta sentencia se ejecutará, regresando al juez de origen para que requiera al demandado el cumplimiento de la misma; mientras que por el proceso de ejecución se apertura o inicia un proceso mucho más expeditivo, con la interposición de una demanda, la misma que siempre debe contener algún documento que tenga el valor de mérito ejecutivo, es decir, que acredite un derecho existente que debe ser cumplido por el ejecutado.
\end{abstract}

\section{ABSTRACT}

This article tries to differentiate when we are within the execution stage of a judicial process as opposed to the execution process. For the first, the procedural iter is developed, begins with the filing of a lawsuit until the issuance of a judgment, the judge will resolve on the conflict declaring founded, unfounded or exceptionally unfounded the claim, this sentence will be executed, returning to the judge of origin to require the defendant to comply with it; while the process of execution opens or initiates a much more expeditious process, with the filing of a lawsuit, which must always contain some document that has the value of executive merit, that is, that establishes an existing right that must be fulfilled by the executed.

\section{PALABRAS CLAVE}

Ejecutoria - etapa ejecutoria- clases de tutela - proceso de ejecución - título ejecutivo- clases de procesos de ejecución.

\section{Introducción}

Por medio del presente artículo se trata de resaltar la importancia del proceso único de ejecución, diferenciarlo de la etapa ejecutoria de un proceso cognitivo, así como determinar cuándo este tipo de tutela ejecutiva es procedente, analizando cada uno de los títulos ejecutivos establecidos de manera cerrada y detallada (numerus clausus) en el artículo $688^{\circ}$ del Código Procesal Civil.

El proceso de ejecución en el contexto del sistema procesal tiene una gran importancia, por cuanto constituye -0 debería constituir-el instrumento para que los acreedores, frente a la renuencia de sus deudores, puedan recuperar en forma efectiva sus créditos. Y de su efectividad, no pocas veces, depende la efectividad misma de todo el sistema procesal. Es más, los procesos de ejecución, en el conjunto de la carga procesal de nuestros Juzgados -tanto de Paz Letrados como Especializados, representan un elevado porcentaje. (Cassasa Casanova , 2011, pág. 5)

Es así que desarrollaremos respecto a las clases de tutela jurisdiccional que existen, aspectos diferenciadores

Abogada y Magister. Árbitro inscrito en el Registro Nacional de Árbitros del OSCE, Arbitra Perú-MINJUS y Consensos PUCP. Docente de la Unifé, Universidad Científica del Sur y Esan y Ricardo Palma. Asociada y Abogada del Instituto Vida, Salud \& Gestión SRL. 
entre la etapa ejecutoria de un proceso de cognición (sea de conocimiento, abreviado o sumarísimo) con el proceso de ejecución en sí mismo, nociones previas al proceso de ejecución, elementos de los títulos ejecutivos y análisis de cada uno de ellos.

\section{Clases de tutela}

El proceso civil constituye una herramienta o instrumento por el que todo sujeto de derecho que se encuentra frente a un conflicto jurídico o con relevancia jurídica tiene expedido su derecho de poder recurrir al órgano jurisdiccional para que éste le resuelva su conflicto. Esto es, tiene expedito su derecho a la tutela jurisdiccional efectiva.

Para Eugenia Ariano, el proceso civil es aquel instrumento puesto por el legislador a fin de que los órganos jurisdiccionales tutelen de los derechos sustanciales de los justiciables. De allí que se hable de "tutela jurisdiccional de los derechos" (Ariano Deho, El proceso de ejecución., 1998, pág. 161)

Y siguiendo a Sergio Casassa, se puede afirmar que "por ello y para la satisfacción de los derechos sustanciales de los justiciables se han desarrollado - clásicamente - tres formas distintas de tutela: la tutela cognitiva, la ejecutiva y la cautelar." (Cassasa Casanova , 2011, pág. 9)

i) La tutela cognitiva: por medio de esta tutela se busca que el Juez conozca los datos, hechos y toda la historia que ha dado origen al conflicto entre las partes. Cada una de las partes deberá probar (ofrecer medios probatorios) lo que alega, señala y expresa y será el Juez quien deberá admitir o rechazar cada medio de prueba ofrecido, posteriormente debe actuar cada uno de los medios probatorios, de ser necesario, y al momento de expedir sentencia debe valorarlos de manera conjunta y razonada. Toda sentencia debe estar debidamente motivada y fundada en derecho. Es decir, el juez resolverá, tomará una decisión, dando la razón o no, a una (si declara fundada o infundada la demanda) o a ninguna de las partes (si es que declara, por ejemplo, improcedente la demanda). Lo cierto es, que en este tipo de procesos el Juez tomará una decisión en base a lo expuesto y probado por las partes.

ii) La tutela ejecutiva: en este tipo de tutela, el juez, ya no pasa del hecho al derecho sino por el contrario en virtud de una sentencia de condena emitida en un proceso de cognición o en base a un documento que la ley le ha conferido el mérito ejecutivo, obtenga el trámite de la actividad jurisdiccional para la concreta satisfacción de su derecho. Es decir, en este tipo de procesos, toda demanda debe ir acompañada de un título de ejecución, título que contiene un derecho a favor del ejecu- tante (demandante) y una obligación o deber para el ejecutado (demandando). En estos procesos no es necesario que el Juez conozca los hechos o datos que dieron lugar al nacimiento del conflicto, en principio, no hay nada que probar, salvo situaciones excepcionales, el proceso es breve, y el ejecutado sólo podrá contradecir el título ejecutivo en causales establecidas de manera detallada por el Código Procesal Civil, caso contrario dicha contradicción sería infundada de pleno derecho.

iii) La tutela cautelar: Este tipo de título tiene por finalidad asegurar o garantizar la eficacia de la sentencia (dentro de un proceso cognitivo) o del auto final (dentro de un proceso único de ejecución).

3. Aspectos diferenciadores de la etapa ejecutoria con la tutela ejecutiva o proceso de ejecución .

Antes de desarrollar sobre el proceso único de ejecución o tutela ejecutiva hay que tener en cuenta que la tutela jurisdiccional efectiva busca que todo justiciable pueda acudir al órgano jurisdiccional en busca de una solución efectiva y eficiente a su conflicto.

La tutela ordinaria o de cognición se caracteriza por sus cinco etapas respectivas (etapa postulatoria, la etapa probatoria (de darse el caso), la etapa decisoria o resolutoria, la etapa impugnatoria y la etapa ejecutoria). La etapa ejecuto- 
ria, consiste en aquella etapa que después que se haya expedido una sentencia (en un proceso de cognición) ésta puede ser cumplida o ejecutada.

"La sentencia pone fin de la etapa donde el justiciable obtiene no solamente aquella pretensión o pretensiones propuestas en los actos postulatorios y sustentados por las pruebas actuadas en la etapa probatoria, sino también la declaración y tutela de la misma, pero para el cumplimiento de la misma se requiere de una etapa posterior para su cumplimiento o ejecución, esta es la llamada etapa ejecutoria, actio judicata o ejecución forzosa" (Rioja Bermudez, 2014, pág. 1209)

La ejecución es la forma práctica de asegurar la eficacia de una sentencia. Para Eduardo Couture "la ejecución permite algo que hasta el momento de la cosa juzgada era imposible: la invasión en la esfera individual ajena y su transformación material para dar satisfacción a los intereses de quien ha sido declarado triunfador en la sentencia [...] debe tenerse presente que este no constituye propiamente un nuevo proceso sino la continuación del proceso ya concluido en vía de ejecución. En tal sentido se ha precisado: Hugo Alsina “... (...) para los fines de su institución, el procedimiento en la ejecución de la sentencia debe ser sumarísimo, no admitiéndose discusiones sobre el derecho decidido en ella, ni dilaciones que contraríen su propósito" toda vez que a fin de que es la sentencia la que debe tener eficacia real y por tanto hacerse efectiva, siendo de este modo, un acto complementario, un efecto reflejo del mismo. (Rioja Bermudez, 2014, pág. 1212) .

Según la jurisprudencia "la ejecución de las sentencias en sus propios términos forma parte del derecho fundamental a la tutela judicial efectiva, ya que en caso contrario las decisiones judiciales y los derechos que en las mismas se reconocen o declaren no serían otra cosa que meras declaraciones de intenciones sin alcance práctico ni efectividad alguna; por tanto la ejecución de las sentencias implica, entre otras cosas, la sujeción de los ciudadanos y de la administración Pública al ordenamiento jurídico y a las decisiones que adopta la jurisdicción. ${ }^{2}$

Mientras que por tutela ejecutiva o proceso único de ejecución, en sede judicial se ha precisado que: Proceso ejecutivo es aquel destinado a hacer efectivo ese derecho [reconocido y cuya cualidad ejecutiva la declara la ley] de tal manera que si en el proceso de conocimiento se parte de una situación de incertidumbre a fin de obtener una decisión jurisdiccional de certeza o la solución a un conflicto intersubjetivo de intereses, en el [...] Proceso ejecutivo se parte de un derecho cierto pero insatisfecho. ${ }^{3}$

En los procesos de ejecución se pretende la efectivización de lo que consta y fluye del título, sin entrar al análisis de las relaciones jurídicas que dieron nacimiento, pues la ley les confiere a ellos la misma fuerza que a una ejecutoria, no pudiendo ordenarse el pago de derechos dudosos o controversiales y distintos a los que indudablemente emerjan del propio título"4

Según Montero Aroca citado por Alexander Rioja, "el proceso de ejecución es aquel en que, partiendo de la pretensión del ejecutante, se realiza por el órgano jurisdiccional una conducta física productora de un cambio real en el mundo exterior para acomodarlo a lo establecido en el título que sirve de fundamento a la pretensión de la parte y a la actuación jurisdiccional". Por su parte. Alsina, señalaba que el proceso de ejecución es "la actividad desarrollada por el órgano jurisdiccional a instancia del acreedor para el cumplimiento de la obligación declarada en la sentencia de condena, en todos los casos que el acreedor no los satisface voluntariamente" (Rioja Bermúdez, 2014, pág. 1217)

Lo cierto y real es que, según Rocco, citado por Casassa Sergio, "normalmente al desarrollo de la acción ejecutiva se procede cuando ya se ha ejercitado la acción de declaración y la de condena, y cuando, a pesar de que el derecho sea ya cierto y se haya dictado la orden al obligado para que cumpla la prestación que le corresponde, éste no se someta al imperio del derecho de modo espontáneo, por lo que el mismo derecho siga violado 
todavía". (Cassasa Casanova, 2011, pág. 10)

Sin embargo, resulta importante precisar que no siempre se llega al proceso único de ejecución después de contar con una sentencia, es decir, después de que haya concluido el desarrollo de un proceso de cognición, pues, muchas veces, la tutela ejecutiva también se ejercita sin que previamente se tenga una sentencia de condena que viene siendo incumplida por el demandado, sino que (la tutela ejecutiva) también, puede iniciarse en base a otro título ejecutivo (laudo arbitral, acta de conciliación con acuerdo total o parcial, un título valor, etc.) títulos que serán analizados posteriormente.

\subsection{Nociones previas al pro- ceso de ejecución}

Para comprender el porqué de este tipo de procesos, es importante tener en cuenta dos aspectos:

a) Qué el titular de la acción, cuente con una sentencia proveniente de un proceso de cognición, que se haya tramitado en la vía de conocimiento, abreviado o sumarísimo; cuente con un laudo arbitral o con un acta de conciliación con acuerdo total o parcial y, que dichos documentos (con lo ahí contenido: decidido-sentencia y laudo-, o acordado por las partes: acta de conciliación con acuerdo) venga siendo incumplida por la otra parte - futuro ejecutado o demandado; $y$, b) Que entre las partes demandante o ejecutante (el acreedor) y la parte demandada o ejecutada (el deudor) haya surgido un vínculo obligacional, y como consecuencia de dicho incumplimiento el acreedor se haya visto obligado a iniciar esta clase de proceso. Es decir, entre las partes surgió una obligación, el deudor no ha cumplido con su prestación (dar, hacer o no hacer) por lo que el acreedor se encuentra facultado para exigírselo judicialmente.

La obligación viene a ser aquel vínculo jurídico o nexo causal que existe entre dos sujetos, uno denominado deudor y el otro, denominado acreedor. El deudor es el titular de la deuda, quien se encuentra obligado, quien tiene el deber de cumplir con el acreedor. El acreedor es el titular del crédito, quien se encuentra facultado o tiene el derecho de exigir dicha obligación al deudor y en caso de incumplimiento puede recurrir al Poder Judicial en busca de tutela, solicitando el cumplimiento de la obligación, más una indemnización por los daños y perjuicios causados. El objeto de la obligación, es la pretensión, es decir, aquella conducta o comportamiento consistente en un dar, hacer o no hacer, dar que puede ser dar un bien cierto o incierto, o una suma de dinero.

Sea cualquiera de estos supuestos el acreedor no se verá perjudicado en su crédito pues, tiene expedito cualquiera de las siguientes acciones establecidas en el artículo 1219 del Código Civil así como poder recurrir al poder judicial en busca de tutela.

De la obligación surgida entre las partes (sea por mandato legal, por voluntad unilateral o por voluntad bilateral), pueda presentarse el supuesto que exista o no, prueba alguna que reconozca dicha obligación.

De no existir prueba alguna, por tratarse de una obligación surgida de manera verbal, el acreedor impago puede solicitar el reconocimiento de dicha obligación sea de manera extrajudicial o judicial o solicitar una prueba anticipada que contenga un documento privado reconocido o copia certificada de la prueba anticipada que contenga una absolución de posiciones sea expresa o ficta.

De existir una constancia del surgimiento de dicha obligación, pueda ser que el acreedor tenga en su poder un documento privado, un documento público o en un título valor o cualquiera de los títulos ejecutivos señalados expresamente en el artículo $688^{\circ}$ del Código Procesal Civil.

En este estado, cuando el acreedor recurre al poder judicial en busca de tutela, ejerciendo su derecho de acción, la relación jurídica de naturaleza obligacional que mantenía con el deudor se convierte en una relación jurídica de naturaleza procesal. El acreedor, dependiendo de la prueba que tenga o no de su préstamo, podrá hacer ejercicio de la tutela ejecutiva, es decir, hacer uso del proceso único de ejecución.

Siendo la ejecución un proceso destinado a satisfacer mate- 
rialmente un derecho (lo que implica una penetrante intromisión en la esfera jurídico patrimonial del ejecutado), para ello se precisa que el derecho a cuya satisfacción está enderezada, sea cierto, vale decir, no deje duda de su existencia (Ariano Deho, Seminario de actualización profesional. , 2008 , pág. 14)

La ejecución forzada es aquella figura en cuya virtud, el órgano jurisdiccional competente, toma todas las medidas necesarias para coaccionar al sujeto pasivo de la resolución, a la realización de la conducta debida, en el supuesto de incumplimiento. En la ejecución forzada, el vencido en la sentencia ha incurrido en una de las causales de incumplimiento de la decisión judicial, situación que abre paso a una etapa del proceso que se orienta a la obtención forzada de la conducta debida por ésta parte, una vez transcurrido el plazo y si la parte no cumpliere la decisión se abrirá esta posibilidad al interior del proceso judicial. Cuando hablamos de la ejecución de sentencias, evocamos esa actividad del Estado coactiva a través de la cual y contra la voluntad del deudor o condenado se cumple lo dictaminado a favor de un acreedor demandante. Esta sentencia para que pueda ejecutarse como tal debe cumplir con ciertos presupuestos y además estar guiada por ciertos principios que abordaremos adelante. En todo caso se trata de un proceso que ineluctablemente vuelve verosímil la labor de tutela por parte del estado en su deber de dar protección jurisdiccional y no meramente declarativa, sino material y tangiblemente real. (Rioja Bermudez, 2014, pág. 1216)

Para Liebman, "La ejecución se ha formado, pues, por la ley como un procedimiento cerrado y perfecto en sí, del cual queda excluida toda indagación de fondo, que camina inexorablemente por su vía, como si no existiese incertidumbre alguna sobre la legitimidad; y, al mismo tiempo, queda a salvo la posibilidad de que desde el exterior (esto con un especial y autónomo proceso de cognición que lleva el nombre de oposición) sobrevenga la orden de detenerse $y$, eventualmente, de restablecer el estado anterior de las cosas. El modo más simple para alcanzar este resultado consistirá en establecer que la ejecución se pudiera pedir solamente sobre la base de una sentencia pasada en autoridad de cosa juzgada; la ejecución resultaría fundada así sobre la plena constatación de la existencia de derecho y la hipótesis de que, no obstante esto, pudiera resultar injustificada quedaría reducida al caso marginal de una extinción del derecho posterior a la formación de la cosa juzgada. Pero ocurre que la ley ha debido tener en cuenta otra exigencia; esto es, la de hacer más rápida la tutela de los derechos del acreedor, y le ha atribuido por eso la posibilidad de pedir la ejecución también en muchos otros casos en los que no hay una verdadera declaración de certeza del derecho, si bien de este modo resulte aumentado el riesgo de emprender una ejecución injustificada" (Liebman, 1980 , págs. 156-157)

\subsection{Función del proceso de ejecución}

El proceso de ejecución, a diferencia del proceso declarativo, no tiene por objeto que el órgano jurisdiccional declare la existencia (o inexistencia) de un determinado derecho en base a lo pretendido, alegado o probado por las partes, sino que tiene por objeto que dicho órgano realice un conjunto de actividades - usualmente materiales -, destinadas a satisfacer concretamente el interés de un sujeto que ya tiene un derecho cierto por cuanto ya ha sido judicialmente declarado o porque la ley lo considera cierto, en sustitución de quien debió hacerlo y no lo hizo (el deudor) (Ariano Deho, Seminario de actualización profesional, 2008 , pág. 13)

El presupuesto para el ejercicio de la acción ejecutiva, lo conocemos como el título ejecutivo, el cual da pie al conocido aforismo: nulla executio sine título, el cual equivale a decir que no puede procederse a la realización coactiva del derecho mediante la acción ejecutiva, sino existe un título ejecutivo. Es precisamente por ello que bajo el impulso de esta acción ejecutiva, inspirada y justificada en un título ejecutivo, el órgano jurisdiccional podrá agredir el patrimonio del deudor y proveerá con dichos bienes, a la satisfacción del derecho del acreedor. (Sergio, Casassa Casanova; Rolando, Martel Chang; Martín, Hurtado Reyes;Marianella, Ledesma Narváez, 2016, pág. 232)

Andolina, citado por Sergio Casassa, señala que el título re- 
presenta un requisito efectivo e incondicionalmente necesario para la realización coactiva del derecho de crédito (Sergio, Casassa Casanova; Rolando, Martel Chang; Martín, Hurtado Reyes;Marianella, Ledesma Narváez, 2016, pág. 233)

Ortelles, citado por Casassa, señala que este título ejecutivo necesariamente deberá tener una plasmación documental, la cual se justifica porque, con esa técnica, el órgano jurisdiccional puede, simplemente comparando el documento con la descripción legal, verificar que se halla ante un título ejecutivo y ordenar que se inicie la actividad ejecutiva, sin necesidad de realizar una actividad de instrucción -alegaciones y prueba- para comprobar si ocurre el supuesto de hecho legal al que se vincula la eficacia ejecutiva (Sergio, Casassa Casanova; Rolando, Martel Chang; Martín, Hurtado Reyes; Marianella, Ledesma Narváez, 2016, pág. 234)

\subsection{Clases de procesos de ejecución}

En razón de las diversidades de prestaciones los procesos de ejecución se distinguen en:

a) Ejecución dineraria, es decir aquella que tiene por objeto satisfacer $a$ un acreedor de dinero, que constituye la más compleja ejecución por cuanto consiste en el conjunto de operaciones que realiza el órgano sobre el patrimonio del deudor (su activo), a fin de obtener el dinero debido (de allí que los italianos la llamen descriptivamente espreopriazione forzata, porque el principal acto es la enajenación forzadas) de los bienes del deudor. Y en,

b) Ejecuciones especificas (no dinerarias), es decir aquellas que tienen por objeto satisfacer a un acreedor de un bien determinado, de un hacer o de un no hacer. Se le llama específica pues se trata de que el órgano jurisdiccional le procure al acreedor el mismo bien de la vida que le debió procurar el deudor (el bien, el resultado del hacer o la abstención) (Ariano Deho , Seminario de actualización profesional, 2008, pág. 14)

La ejecución de la sentencia forma parte del debido proceso, de la garantía de la tutela jurisdiccional efectiva, la cual se encuentra establecida en nuestra Constitución Política del Perú, es decir, la justicia se encontrará cuando la sentencia sea efectivamente ejecutada, es decir, "existirá una justicia completa cuando esta logre alcanzar la certeza de que lo resuelto no solamente constituya en una simple decisión judicial sino que se materialice con el acatamiento de lo resuelto sea por propia voluntad del vencido o a través del cumplimiento forzoso de la sentencia, mediante los instrumentos que concede la norma. (Rioja Bermúdez, 2014, pág. 1215)

\section{4. ¿Qué hace que un documen- to tenga mérito ejecutivo?}

¿Qué es el título ejecutivo? La doctrina contemporánea, tras mil y una polémica al respecto, ha llegado a la conclusión escéptica: no es posible dar una noción unitaria y atípica de título ejecutivo. De ello se hace eco Montero Aroca, cuando señala que "el título ejecutivo no es una categoría. Documentos título ejecutivo son los que el legislador quiere que sean; atendiendo a razones de oportunidad política, el legislador atribuye a determinados documentos la cualidad de título ejecutivo y nada más. Un concepto atípico o general carece de utilidad. Se debe hacer un enumeración (siempre numerus clausus), pero no buscar una noción (Ariano Deho, Seminario de actualización profesional, 2008 , pág. 15)

Título ejecutivo es un documento al que la ley le concede la calidad de tal (artículo 688 del Código Procesal Civil) en tanto contenga un derecho expreso cierto y exigible (689 $\mathrm{CPC}$ )

De la Oliva Santos refiere "Lo que convierte un documento en título ejecutivo es una disposición expresa de la ley, que puede estar fundamentada en muy diversas razones. Sin embargo, la ley no puede crear un título ejecutivo sobre cualquier base, sino sobre la base de un documento susceptible de desempeñar las funciones siguientes: 1) fundamentar, directa o indirectamente la actuación de sanciones (consecuencia de la infracción de deberes), ii) determinar la legitimación activa y pasiva, esto es, indicar quién puede pretender la tutela jurisdiccional ejecutiva y frente a quien; iii) delimitar el contenido, sentido, medida o alcance de los actos jurisdiccionales ejecutivo" (De la Oliva Santos , 2002, pág. 35) 


\subsection{Elementos del título eje- cutivo}

Siguiendo a Eugenia Ariano, podemos expresar que todo título ejecutivo cuenta con un elemento formal y otro sustancial.

-El Elemento formal. El documento. El título es antes que nada un documento. Un documento es un objeto (una cosa) que representa un hecho. [...[ solo son títulos ejecutivos los señalados como tal por la ley.

-Elemento sustancial: si un documento es un objeto que representa un hecho, para que el documento señalado por ley sea idóneo para constituir un título ejecutivo necesita que lo que represente sea un acto (cualquiera o determinado por la propia ley) que sea la fuente generadora de una obligación; vale decir, que el documento debe representar una relación obligatoria. Pero no basta. Se requiere que los elementos de la relación obligatoria (tanto subjetivos como objetivos) sean ciertos, y su objeto (la prestación) sea expresa y exigible. Por cierto es todo lo que no deja duda sobre su alcance. Es cierta una obligación cuando deudor y acreedor están plenamente identificados así como la prestación. Es expresa cuando los elementos de la relación obligacional se desprenden del mismo documento, de su tenor textual. Es exigible cuando la obligación se presenta en el tenor textual pura o estando sometida a modalidad (plazo o condición) el plazo haya vencido o se haya cumplido la condición. (Ariano Deho,
Seminario de actualización profesional. , 2008 , pág. 16)

4.2. Títulos ejecutivos de naturaleza judicial y de naturaleza extrajudicial y otros títulos

Según el artículo $688^{\circ}$ del Código Procesal Civil, se pueden advertir los siguientes títulos ejecutivos:

\section{Títulos ejecutivos de natura- leza judicial.-}

Inciso 1. Las resoluciones judiciales firmes: dentro de las resoluciones judiciales firmes, podemos comprender a "las sentencias de condenas firmes: el título ejecutivo por excelencia. Y se precisa que deben ser sentencias de condena por cuanto las sentencias absolutorias, o meramente declarativas o constitutivas no son susceptibles de ejecución [...] los autos que fijan el cumplimiento de una prestación u obligación: en este rubro tenemos aquellas resoluciones en donde se impongan multas, costas, condenas en perjuicio de los litigantes como por ejemplo: i) el auto que declara concluido el proceso por conciliación; ii) el auto que aprueba la transacción judicial; iii) el auto que pone fin al proceso en cuanto a las costas [...] (Sergio, Casassa Casanova; Rolando, Martel Chang; Martín, Hurtado Reyes;Marianella, Ledesma Narváez, 2016, pág. 237)

Inciso 2. Los laudos arbitrales firmes: "es precisamente el laudo arbitral, el cual ha sido equiparado a una sentencia firme, la pieza procesal que contiene la decisión defini- tiva y por ello la que tendrá que hacerse cumplir - cuando nos referimos a un laudo con contenga pretensión de condena-tanto en el mismo proceso arbitral o en su defecto en sede judicial, conforme lo establece el artículo 67 de la Ley de Arbitraje (Sergio, Casassa Casanova; Rolando, Martel Chang; Martín, Hurtado Reyes;Marianella, Ledesma Narváez, 2016, pág. 238). El laudo arbitral viene a ser aquella decisión final, definitiva, inapelable y vinculante expedida por un tribunal arbitral (único o colegiado) en aquellos conflictos de derechos disponibles que las partes someten a su consideración por medio de un convenio arbitral, cualquiera sea la forma que ésta asuma.

Los títulos ejecutivos de naturaleza extrajudicial.-

Inciso 3. Las actas de Conciliación de acuerdo a Ley: $\mathrm{El}$ contenido de la misma se encuentra condicionada -bajo sanción de nulidad- a la formalidad que prevé el artículo 16 de la Ley 26872, modificada por Decreto Legislativo 1070. Entendamos que se refiere a aquellas actas de conciliación con acuerdo total o parcial, las mismas que tienen valor de sentencia fundada. Se recurre a la conciliación extrajudicial cuando haya surgido un conflicto entre las partes, siempre que se trate de un derecho de naturaleza disponible. Únicamente, si las partes arriban a un acuerdo (sea de todas las pretensiones solicitadas o sólo alguna de ellas) con la ayuda de un Conciliador extrajudicial, ésta acta tendrá el valor de título ejecutivo. 
Inciso 4. Los títulos valores que confieran la acción cambiaria, debidamente protestados o con la constancia de la formalidad sustitutoria del protesto respectiva; o, en su caso, con prescindencia de dicho protesto o constancia, conforme a lo previsto en la ley de la materia.

Inciso 5. La constancia de inscripción y titularidad expedida por la Institución de Compensación y Liquidación de Valores, en el caso de valores representados por anotación en cuenta, por los derechos que den lugar al ejercicio de la acción cambiaria, conforme a lo previsto en la ley de la materia. "estas anotaciones [...] son una vieja práctica bancaria que consiste en inmovilizar los títulos con soporte de papel, físicamente. Las transferencias se hacen con la simple anotación en un libro de Registros de Depósitos del Banco. No hay manipulación material de los títulos. Para prever la transferencia entre banco y banco, se reguló la centralización de los depósitos en bancos colectores (depósito en segundo grado). Aquí los bancos perdían la posibilidad inmediata de la cartera de depósitos y pasaban a los bancos colectores. Hoy esa función es realizada por la institución de Compensación Liquidación en Valores, CAVALI, que es una sociedad anónima que tiene por objeto exclusivo el registro, custodia, compensación, liquidación y transferencia de valores. (Ledesma Narvaéz , 2008, pág. 365)

Inciso 6. La prueba anticipada que contiene un documento privado reconocido e Inciso.
7. La copia certificada de la Prueba anticipada que contiene una absolución de posiciones: "el Código Procesal Civil le atribuye la calidad de títulos ejecutivos tanto al reconocimiento y absolución de posiciones que provengan de una prueba anticipada. En estos casos el título ejecutivo debería estar conformado por el expediente -tanto del reconocimiento como el de la absolución de posiciones-; sin embargo y conforme se aprecia del inciso 7 del artículo 688, el título ejecutivo, erróneamente se refiere a la copia certificada que contiene una absolución de posiciones. (Sergio, Casassa Casanova; Rolando, Martel Chang; Martín, Hurtado Reyes;Marianella, Ledesma Narváez, 2016, pág. 242)

Para Ledesma, la prueba anticipada es un procedimiento orientado a facilitar la vida del proceso principal, agrupándose en dos categorías, la diligencias preparatorias y las diligencias conservatorias de prueba en atención a la finalidad que se persigue (Ledesma Narvaéz , 2008, pág. 366)

Inciso 8. El documento privado que contenga transacción extrajudicial: $Y$ es que a decir del artículo 1302 del Código Civil, por la transacción las partes, haciéndose concesiones réciprocas, deciden sobre algún asunto dudoso o litigioso, evitando el pleito que podría promoverse o finalizando el que está iniciado. Por ello el propio Código Civil, en su artículo 1312 , le confiere mérito ejecutivo a la transacción extrajudicial, y en virtud de ello el Código Procesal Civil recoge que el documento privado que contenga dicha transacción, entiéndase extrajudicial, se le confiere mérito ejecutivo. No se trata que dicha transacción requiera intervención notarial, ya que la norma requiere que dicho acto se encuentre contenido solo en un documento privado, con lo cual queda claro que tendrá mérito ejecutivo aquel documento privado que contenga una transacción extrajudicial. (Sergio, Casassa Casanova; Rolando, Martel Chang; Martín, Hurtado Reyes; Marianella, Ledesma Narváez, 2016, págs. 242-243)

Inciso 9. El documento impago de renta por arrendamiento, siempre que se acredite instrumentalmente la relación contractual

Inciso 10. El testimonio de escritura pública: "La escritura pública es un título ejecutivo en tanto que el acto contenido en él contenga una obligación cierta, expresa y exigible. La ley le confiere mérito ejecutivo atendiendo aquella presunción de certeza que los documentos escriturados contienen en mérito a la intervención notarial. (Sergio, Casassa Casanova; Rolando, Martel Chang; Martín, Hurtado Reyes; Marianella, Ledesma Narváez, 2016, pág. 243)

Inciso 11. Otros títulos a los que la ley les da mérito ejecutivo: Siguiendo a Sergio Cassasa, se puede afirmar, que tenemos un sinnúmero de títulos ejecutivos dispersos en nuestro ordenamiento jurídico, enumeraremos algunos:

El extremo de la resolución final que ordena el cum- 
plimiento de una medida correctiva reparadora a favor del consumidor, una vez que quedan consentidas o causan estado en la vía administrativa. La legitimidad para obrar en estos casos corresponderá a los consumidores beneficiados con la medida correctiva reparadora (artículo 115.6 del Código de Protección y Defensa del Consumidor)

Las liquidaciones de saldos deudores de las entidades del sistema financiero (artículo 132 inciso 7 de la Ley 26702)

- Letra de cambio a la vista (artículo 228 de la Ley 26702)

- Las liquidaciones para cobranza (artículo 37 de la Ley del Sistema Privado de Pensiones, TUO de la Ley, DS 094-97-EF, modificado por ley 28470)

- Obligaciones adeudadas a la Caja de Beneficios y Seguridad Social del Pescador (Ley 27301

- Instrumentos impagos por la cobranza de las cuotas ordinarias y/o extraordinarias de unidades inmobiliarias de propiedad exclusiva y de propiedad común (Ley 27157 del artículo 50)

- Los recibos por servicio de agua potable y saneamiento (D. Legislativo 908, artículo 23 Ley General de Servicios de Saneamiento)

- La escritura pública del contrato de arrendamiento financiero (leasing)
(Decreto Legislativo 219, artículo 10)

- Actas de juntas de acreedores, debidamente certificadas, respecto de la ejecución de acuerdos relacionados al nombramiento y asunción de funciones de administradores $\mathrm{y} / \mathrm{o}$ liquidadores (Ley General del Sistema Concursal, artículo 55.3)

\section{Conclusiones}

-Existen tres clases de tutela: la cognitiva, la ejecutiva y la cautelar. En los procesos de ejecución no es necesario que el Juez conozca los hechos o datos que dieron lugar al nacimiento del conflicto, en principio, no hay nada que probar, salvo situaciones excepcionales, el proceso es breve, y el ejecutado sólo podrá contradecir el título ejecutivo en causales establecidas de manera detallada por el Código Procesal Civil, caso contrario dicha contradicción sería infundada de pleno derecho.

-La tutela ordinaria o de cognición se caracteriza por sus cinco etapas respectivas (etapa postulatoria, la etapa probatoria (de darse el caso), la etapa decisoria o resolutoria, la etapa impugnatoria y la etapa ejecutoria). La etapa ejecutoria, consiste en aquella etapa que después que se haya expedido una sentencia (en un proceso de cognición) ésta puede ser cumplida o ejecutada.

-El Proceso ejecutivo es aquel destinado a hacer efectivo ese derecho [reconocido y cuya cualidad ejecutiva la declara la ley] de tal manera que si en el proceso de conocimiento se pate de una situación de incertidumbre a fin de obtener una decisión jurisdiccional de certeza o la solución a un conflicto intersubjetivo de intereses, en el proceso ejecutivo se parte de un derecho cierto pero insatisfecho

-El proceso de ejecución tiene por objeto que el órgano jurisdiccional realice un conjunto de actividades - usualmente materiales -, destinadas a satisfacer concretamente el interés de un sujeto que ya tiene un derecho cierto por cuanto ya ha sido judicialmente declarado o porque la ley lo considera cierto, en sustitución de quien debió hacerlo y no lo hizo (el deudor) (Ariano Deho, Seminario de actualización profesional. , 2008 , pág. 13)

\section{Referencias Bibliográficas}

-Ariano Deho, E. (2008 ). Seminario de actualización profesional. Información especializada para abogados y jueces . Lima, Perú : Gaceta Jurídica .

-Ariano Deho, E. (1998). El proceso de ejecución. Lima: Rodhas.

-Cassasa Casanova , S. (2011). El debido proceso de ejecución de obligación de dar suma de dinero:

en busca de un proceso justodoi:http: // tesis.pucp.edu. pe/repositorio/bitstream / handle/123456789/5253/CASASSA_CASANOASERGIO_DEBIDO_PROCESO.pdf?sequence=1.

-De la Oliva Santos, A. (2002). Derecho Procesal Civil. Ejecución forzosa - procesos especiales (2da ed.). Madrid: Centro de estudios Ramón Areces. 
-Ledesma Narváez , M. (2008). Comentarios al Código Procesal Civil (Vol. III). Lima: Gaceta Jurídica.

-Liebman, E. T. (1980). Manual de Derecho Procesal Civil . Buenos Aires : EJEA.
- Rioja Bermudez, A. (2014). Derecho Procesal Civil - Teoría General, Doctrina y Jurisprudencia.

Lima: Adrus editores.
-Sergio, Casassa Casanova; Rolando, Martel Chang; Martín, Hurtado Reyes; Marianella, Ledesma

Narváez. (2016). Código Procesal Civil Comentado (Vol. V). Lima: Gaceta Jurídica. 